Article

\title{
The Food For Life Catering Mark: Implementing the Sustainability Transition in University Food Procurement
}

\author{
Lori Stahlbrand \\ Geography Department, Wilfrid Laurier University, Waterloo, ON N2L 3C5, Canada; \\ lori.stahlbrand@gmail.com; Tel.: +1-416-407-0725 \\ Academic Editors: Giaime Berti, Moya Kneafsey, Larry Lev, Irene Monasterolo and Sergio Schneider \\ Received: 13 June 2016; Accepted: 9 September 2016; Published: 14 September 2016
}

\begin{abstract}
This article presents a case study of the application of the Soil Association's Food For Life Catering Mark at two universities in England: Nottingham Trent University and University of the Arts London. This procurement initiative has had noteworthy success in the U.K., with more than 1.6 million Catering Mark meals served each weekday. This article, based on 31 in-depth interviews conducted in 2015, is the first to examine its impact and significance at the university level. In particular, this article tests the concepts of the niche, regime and landscape in the multi-level perspective (MLP), a prominent theoretical approach to sustainability transition, against the experience of the Food For Life Catering Mark. The article confirms the importance of the landscape level of the MLP in the food sustainability transition, while adding additional considerations that need to be specified when applying the MLP to the food sector. By highlighting the essential role of civil society organizations (CSOs), public institutions and many champions, this article proposes that more room must be made within the MLP for the explicit role of agency, champions and the implementation process itself. Indeed, this article argues that implementation, the daily practice, is deserving of both increased recognition and theory.
\end{abstract}

Keywords: public sector food procurement; sustainability; local food; sustainable food; university catering; Food For Life Catering Mark; sustainability transition theory

\section{Introduction}

The potential of public purchasing to foster sustainable food systems has aroused considerable interest in recent years, especially in Europe and North America. The power of what Morgan et al. call "the public plate" [1], long overlooked as a public policy tool, is now winning support.

There are four reasons for this. First, public purchasing is significant. In the U.K., more than $£ 2$ billion are spent each year on public sector food and catering [2]. Second, public purchasing relates to a change in lifestyles. It is estimated that as much as $43 \%$ of all meals are eaten outside of the home [3,4], often at schools, hospitals, universities and other public settings. At a time when this trend is growing, public purpose institutions need to be highlighted as sites of transition. Third, aside from the amount of money involved, public purchasing brings the power of public policy and public institutions to the foreground of sustainable thinking and strategy. This is a major departure from putting the onus of leadership and responsibility on individual citizens who are inspired to change the food system "one bite at a time" by "voting with one's fork". Fourth, from an economic development perspective, the increased attention to public food procurement is noteworthy because it identifies a unique opportunity to scale up the production of and demand for sustainable and local food [1,5-7].

To date, much of the trend toward sustainable food purchasing has been happening within educational institutions. The greatest number and most publicized of these projects have been in 
primary and secondary schools [8-15]. Though lacking in profile, post-secondary institutions have also been doing solid work and offer a different understanding of the potential of public procurement. Action at the school level in the U.K. was motivated largely by a concern for the health and nutrition of British school children. At the university level, the significant motivating factor has been to highlight sustainability efforts. This article investigates transitions to more sustainable and local food systems, and therefore, the university experience is more relevant.

This article presents information and analysis on two of these efforts, both associated with the British-based Soil Association and its Food For Life Program in London and Nottingham. The U.K.'s Food For Life Program and the accompanying Food For Life Catering Mark are among the most prominent and successful of these initiatives. The Program and the Catering Mark are projects of the Soil Association (which calls itself "the UK's leading membership charity campaigning for healthy, humane and sustainable food, farming and land use" [16]), in partnership with three other national charities. These projects have the potential to serve as a model for scaling up and out sustainable procurement for the entire public sector in the U.K. and elsewhere.

The Food For Life Catering Mark is a pivotal element of the offering. It is a self-financing, third-party certification system that supports the goals of the Food For Life Program. At the time of writing, 1.6 million Catering Mark-certified meals are served throughout the U.K. each weekday. These are offered in a variety of settings, including universities, hospitals and childcare centres. According to Rob Percival, a Soil Association Policy Officer, the Catering Mark represents a deliberate attempt to shift responsibility for sustainability transition in the food system away from individual consumers and towards the public realm [17]. The Soil Association also identifies food culture as significant. Percival points out that the Soil Association's efforts are meant to transform not only the quality, but also the culture and discourse around food served on public plates.

The Food For Life Catering Mark is part of a "refreshed strategy" for the Soil Association, made public in a 2011 report entitled The Road to 2020: Towards healthy, humane and sustainable food, farming and land use [18]. In the introduction to the report, Helen Browning, Chief Executive of the Soil Association, emphasizes the need to reach out to people "to show the relevance of our work, even for those who are not eating or producing organically". She argues that "our role in public health should be as powerful as in the environment and farming." [18].

This article is the first to examine the agenda and workings of the Food For Life Catering Mark at the university level. The article presents the Catering Mark as a sociotechnical innovation, with potential to serve as an important site of the emerging sustainability transition in food. Since its launch in 2009, the Catering Mark has been taken up by 40 universities across the U.K. The article examines two English universities, Nottingham Trent University (a university of 27,000 in the Midlands city of Nottingham) and University of the Arts London (a multi-campus university of 26,000 students based in London), where the Food For Life Catering Mark has been adopted. These two universities have been among the most successful at implementing the program and achieving advanced standing in the certification. They were also selected because they represent two different approaches to foodservice common among public sector institutions: the self-catered model and the contracting out model.

The richness of the Food For Life Catering Mark experience allows this article to present the dynamism, complexity, detail and nuance necessary for a robust analysis of sustainability transition theory as applied to food. In particular, this article uses the multi-level perspective (MLP), a prominent theoretical approach to sustainability transition. The MLP posits that transitions result from interactions among three levels—niches, regimes and landscapes—which eventually lead to a sociotechnical "regime shift". According to classic MLP statements, niches are "protected spaces" where innovations can be nurtured, tested and strengthened to the point where they can challenge a regime [19]. Regimes are defined as the critical meso-level, including practices, policies, infrastructure and interests", the specific rules of the game" that the innovation can disrupt [20]. The landscape is 
the broader context—social, institutional, technical and environmental-that affects developments within niches and regimes.

This article tests the MLP concepts of niche, regime and landscape against the experience of the Food For Life Catering Mark. The article confirms the importance of the landscape level of the MLP in the food sustainability transition, while adding additional considerations that need to be specified when applying the MLP to the food sector. Notwithstanding important insights of the MLP approach, the author's assessment of the Food For Life Catering Mark testifies to the central importance of human agency and champions, a notion still under development in the MLP. This article uses the word "champion" as defined in the Business Dictionary. A champion is a person "who voluntarily takes extraordinary interest in the adoption, implementation and success of a cause, policy, program, project or product" [21]. A champion might also be called a "change agent". Being a champion or change agent is distinct from similar terms, such as "leader" or "advocate", neither of whom are usually involved in day to day program implementation. The champion embodies agency, a major resource of the transition experience.

The article proceeds as follows. It begins by discussing the methodology used for this research and then provides background information as to the origins of the Food For Life Program and the emergence of the Food For Life Catering Mark. The case studies of Nottingham Trent University and the University of the Arts London are presented. The article then applies the MLP framework, first by examining landscape factors and then by adding to the conceptualization of the niche. The article concludes by positing that the practice of foodservice deserves to be theorized.

The MLP has been criticized for neglecting the role of human agency in sustainability transitions [22-26]. Geels has responded that agency is already incorporated and claims that the MLP is "shot through with agency because the trajectories and multi-level alignments are always enacted by social groups" [27]. This article argues that the MLP would be enriched by foregrounding agency, a proposition that is germane to recent amendments made to the MLP model by Geels himself [28]. The article argues that agency in food system work goes beyond a supporting or aligning role and proactively initiates regime change. By highlighting the essential role of civil society organizations (CSOs), public institutions and many champions, this article proposes that more room must be made within the MLP for the explicit role of agency, champions and the implementation process itself. Indeed, this article argues that operationalization and implementation of the sociotechnical innovation, the daily practice, is deserving of both recognition and theory.

\section{Materials and Methods}

This article is based on 31 in-depth semi-structured interviews conducted in 2015. Administrators, chefs and other staff at the two universities under analysis were interviewed, as well as farmers, distributors and processors who supply the universities. Interviews were also conducted with staff from two civil society organizations central to the establishment of the Food For Life Catering Mark at the two universities - the Soil Association and People and Planet, which describes itself as "the largest student network in Britain campaigning to end world poverty, defend human rights and protect the environment" [29]. In addition to the interviews, multiple data sources were used, including scholarly articles, web pages, reports, government documents, standards protocols and other operations material, as well as personal observations during tours, tastings and events.

There is a personal story behind the author's approach to information-gathering during qualitative interviews. First, the author was the founder and president for almost a decade of a Canadian civil society organization, Local Food Plus, which initiated a major procurement project featuring local sustainable food at the University of Toronto. Having herself wrestled with the cascade of operational challenges faced by interview subjects, she prompted interviewees for memories of their dealings of this oft-overlooked level of policy implementation. One example is the interview with Food For Life Catering Mark Project Manager Jen Collins on page 17 about sourcing free-range eggs [30]. As a former practitioner, the author knows the complexity of egg supply chains and understood immediately 
why assessing the availability of free-range eggs posed a significant challenge. At a broader level, Catering Mark staff members were aware of the author's work as a practitioner in Canada. As a result, senior staff made themselves available for lengthy conversations, which they treated as exploratory discussions rather than scripted interviews.

Secondly, the author also worked for 15 years as a senior journalist and broadcaster with the Canadian Broadcasting Corporation ( $\mathrm{CBC}$ ). In the course of this work, she honed the skills of open-ended semi-structured interviews designed to draw people out of scripted or superficial responses about formal policy decisions and to plumb the depths of insight and vivid details behind what happened. These interview techniques explored the lived lives of sustainability practitioners and how their personal responses and insights influenced sustainable food practices. The resulting interviews reveal a lively sense of people rooted in an experience of food policy facing the test of implementation. A background of praxis in gathering information and analysis about sustainable food practice is valued by methodology scholars, such as Morse, who recognizes the special need for qualitative researchers to bring "much knowledge about what they are observing or hearing, know and be able to link it to relevant literature, and be able to think conceptually and to link seemingly unconnected events, representations, and ideas" [31].

\section{Background}

\subsection{The Origins of the Food For Life Program}

The Food For Life Catering Mark is closely linked with the Food For Life Program, a program led by the Soil Association, which aims at "transforming food culture" in British schools to focus on health, sustainability and enjoyment [32]. In 2003, the Soil Association produced a report entitled Food For Life: healthy, local, organic school meals, which focused on the poor quality of food, "muck off a truck" served in English schools [33]. The report is a clarion call for change. It begins with this assertion: "For more than two decades, minimal regulation has meant that attractive, tasty and nutritious school meals made from quality ingredients have been sacrificed in favour of competition, convenience and cost" [33].

The report recommended that the government develop and monitor standards for nutrition in primary school meals and provide guidance and training for catering staff to meet targets of $30 \%$ organic food, $50 \%$ locally-sourced food and $75 \%$ food prepared from unprocessed ingredients. In addition, the report called for a new food culture in schools, with specified curriculum changes so that children could learn where their food comes from and how it is produced and prepared. The report also included a call for an overhaul of the school food supply chain. "These changes will play a crucial part in helping to secure a sustainable future for British food and farming," the report concludes. "Above all, these changes are desperately urgent if we are to prevent the escalating, diet-related disease burden now threatening the well-being of an entire generation." [33].

This report is notable as an early example of a prominent organization identifying public food procurement as a critical tool in sustainability transition. The report is also prescient in its comprehensive integration of environmental health and cultural change, thereby opening the door to a wider analysis of the food system, beyond the particulars of organic certification. Such outreach also opened the door to a wider set of relationships and flexibility in standards-setting, a decisive strategic decision, as will become clear later in this article.

The Food For Life Partnership was launched in 2007 with $£ 16.9$ million in multi-year funding from The Big Lottery Fund, "the largest distributor of National Lottery good cause funding" [34], an extraordinarily generous grant by international standards. The project explicitly recognized that issues such as obesity, chronic disease and climate change could not be addressed unless food culture was transformed and individuals and communities regained food skills and knowledge. The partnership that emerged was a consortium of national charities, led by the Soil Association, conceived of to reconnect people with their food and "to revolutionise school meals, to ensure children can concentrate and achieve, and to inspire young people and their families to eat, cook and grow 
healthy and sustainable food" [32]. The program is based on a tiered award scheme that encourages schools to work towards bronze, silver and gold awards. Evaluation includes four sets of criteria: (1) food leadership; (2) food quality and provenance; (3) food education; and (4) food culture and community involvement.

The University of the West of England and Cardiff University were commissioned to provide an evaluation of the partnership. By the time the report was released in 2011, more than 3000 schools had joined the program [32]. The evaluation results were impressive. They indicated increases in school meal uptake and fruit and vegetable consumption, as well as student involvement in gardening, cooking, visiting farms and other experiential learning around food.

The program coincided with the publicity that celebrity chef Jamie Oliver brought to the poor quality of school meals in Britain. Jeanette Orrey, a "dinner lady" at a primary school in Nottinghamshire, is credited with inspiring Oliver to take up a school meal campaign. Orrey recalls that the food she was being asked to serve was so vile that "none of my staff would eat the food. If we wouldn't eat it, why did we expect the children to eat it." [35]. In 2000, Orrey decided to start cooking from scratch with local whole ingredients. She "literally got into [her] car and went to see the farmers". The reaction from children and parents was enthusiastic, and Orrey went on to become one of the founders of the Food For Life Program. Today, Orrey is the Soil Association's School Meals Policy Advisor and a champion for ending food poverty in the U.K.

An added benefit of the Food For Life Program has been its impact on local economies. In 2011, the New Economics Foundation issued a report that focused on the impact of the Food For Life Program in Nottinghamshire and Plymouth. The study reviews the positive impacts of the quality of food being served at school meals, but emphasized the significant impact on local economies, resulting from an increase in seasonal food procurement. The program yielded a return of more than $£ 3$ in social, economic and environmental value for every $£ 1$ spent, according to the report [36].

\subsection{The Emergence of the Food For Life Catering Mark}

It soon became clear that many school caterers needed guidance and resources on ways to transition their operations to meet the Food For Life Program goals, challenging goals that involved preparing food with more fresh, seasonal, local and organic ingredients, as well as sustainably-raised meat and fish that met animal welfare standards. In 2009, the Food For Life Catering Mark was launched to support this complex transition. This civil-society led procurement initiative, like the Food For Life Program itself, provides a ladder to move through bronze, silver and gold levels. The ladder is based on four principles: (1) serve fresh food; (2) source environmentally-sustainable and ethical food; (3) make healthy eating easy; and (4) champion local food producers [37]. The standards are overseen by an autonomous Standards Committee housed at the Soil Association Charity. The third-party certification is managed by Soil Association Certification Ltd, a non-profit subsidiary of the charity, and financed through charges for inspections and licensing fees.

The bronze level is a fixed standard, with twelve compulsory elements covering a full gamut of requirements. The standards specify that at least $75 \%$ of dishes on the menu must be freshly prepared from unprocessed ingredients; that all meat, fish and eggs meet certain ethical and/or environmental standards; that no genetically-modified organisms, trans fats or artificial additives are used; that menus are seasonal and meet dietary and cultural needs; that free drinking water is available; that food safety protocols are in place; that staff receive training in how to prepare meals made from fresh foods; and that information about the food's provenance is on display [37]. There is no requirement to source any certified organic food at the entry (bronze) level, recognition that the work of implementing the Catering Mark was a major step for most caterers. In addition, because of European Union regulations, there is no specific requirement to use local food, although Project Manager Jen Collins says an increase in local food is often an outcome when institutions purchase more fresh and seasonal food [30].

The silver and gold level awards are point-based. Silver and gold caterers must meet all of the bronze requirements and also go beyond these standards in three categories, including: (1) ethical and 
environmentally-friendly food; (2) making healthy eating easy; and (3) championing local producers. Caterers can score extra points by encouraging lower meat consumption, minimizing salt, offering more fruit-based desserts and related public health priorities. In addition, they must spend at least $5 \%$ of their food budget on organic produce to achieve the silver mark and $15 \%$ to achieve gold.

There is also a Catering Mark Supplier Scheme. According to Suzi Shingler, Catering Mark Relationship Manager, the idea behind the Supplier Scheme is to make it easier for caterers to access food that meets Catering Mark standards and for suppliers who meet Catering Mark standards to take advantage of sales opportunities opened by the Catering Mark [38]. A designated staff member at the Soil Association provides support to these suppliers, including webinars, advice, training and marketing materials. There are currently more than 170 members of the Catering Mark Supplier Scheme. According to the Supplier Scheme webpage, members have reported up to $20 \%$ increases in sales after joining the scheme [39]. Member companies supply a wide range of products, including meat, dairy, eggs and produce, as well as an assortment of products as varied as stocks, marinades flour, sugar, tuna, pesto, oats, pizza dough, granola, tofu and herbs and spices.

The distinguishing feature of the Catering Mark is its provision of what food scholar Kevin Morgan would call a "big tent where there is room for everybody", something Morgan deems essential if food is to exert its real power [40]. This is achieved by recognizing a number of existing quality, sustainability, animal welfare and farm assurance (traceability) schemes in the U.K., including Red Tractor Assurance, Freedom Food, Fairtrade, Organic and Marine Stewardship Council. Incorporating existing certifications and farm assurance schemes helped bring the conventional agricultural community on board as allies, according to Policy Officer Rob Percival [17]. In addition, according to Project Manager Jen Collins, "one of the strengths of the catering mark is that it brings all of these best practice standards together." [30]. However, Collins emphasizes that the Catering Mark is menu-based, with a focus on health and culture. For this reason, it does not address issues such as waste, energy or wages. Collins says caterers looking for guidance in these areas are directed toward expert organizations in the U.K. already working on these issues.

For the Soil Association, which runs the U.K.'s largest organic certification program, the decision to develop a catering mark that did not insist on organic food at the entry level provoked turmoil within the organization, especially after the release of The Road to 2020 in 2011, which stressed the commitment to "start where people are" [18]. This internal conflict eventually led to resignations of several board members [41,42]. Policy Officer Rob Percival's words, echoed in several other interviews, emphasize that the Catering Mark is designed as a ladder for engagement, which deliberately reduces barriers to entry. Percival says "starting where people are" means "you draw them into a framework of continuous improvement. Organic may be the gold standard, but this is where people begin" [17]. This might mean starting by shifting away from highly-processed food or developing a direct relationship with a food producer. Project Manager Jen Collins argues that even achieving the bronze standard is a big leap for many caterers. "We see caterers going from a $35 \%$ freshly-prepared menu to $75 \%$. It's a real change in how they're making the food, the sort of practices they're putting into play-it's completely different", she says. Collins uses the metaphor of a runner. "When you start running, you don't enter a marathon the week after you buy your first trainers. You have to work your way up and build your fitness. It's similar with the Catering Mark. It's making those changes and realizing that you can do it. That's why the bronze, silver, gold approach works so well" [30].

The development of the Catering Mark can be seen as an indication of the shrewdness and maturity of the Soil Association. The organization had come to the point where staff knew that they could no longer just proclaim goals or state a policy. They understood that they were breaking into a hegemonic food regime and that they needed to develop momentum that could carry policy along an extended supply chain, set with many tripwires, in order to win ground. As The Road to 2020 states, "Food For Life has demonstrated that 'starting where people are' and providing easy first steps to engage with people can be incredibly powerful. We need to listen to people, understand where they are coming from and find creative ways to engage them in our work and our ideas" [18]. 


\section{Case Studies}

Forty universities currently hold the Catering Mark for some aspect of their food offerings, be it a small campus pub or a large full-service cafeteria. According to the Catering Mark website, 32,000 certified meals are served in U.K. universities each workday [43]. The case studies profiled here represent two types of university catering-in-house (self-catered), as is the case with Nottingham Trent University, and contracted foodservice provider, as is the case with University of the Arts London, which contracts with BaxterStorey. BaxterStorey is a U.K.-owned catering company founded in 2004 with a commitment to fresh, local, seasonal food, according to Operations Manager John Wood [44]. Nottingham Trent was the first university in the U.K. to achieve the silver award and consistently scores in the top five on the People and Planet University League table of university sustainability. University of the Arts London was the first university in the U.K. to achieve the gold award.

\subsection{Nottingham Trent University}

Nottingham Trent University (NTU) is located in the heart of the Midlands city of Nottingham, a community of about 500,000 , surrounded by fertile farmland and charming villages. The University does all its catering in-house, serving about 2500 meals each day, 1000 of which are certified by the Food For Life Catering Mark. Ivan Hopkins, the former Executive Chef who now heads Catering and Hospitality, has been the driving force behind the implementation of the Catering Mark at NTU.

"We just can't do that," was Hopkins' initial reaction, after speaking with a local hospital manager who used the Catering Mark. "But then I sat and thought about it, and I realized that we were already doing many of the things required by the Catering Mark, but we weren't communicating it to customers. It seemed a shame not to get recognition for it." [45]. Hopkins recognized that the goals of the Catering Mark were akin to his own views, that "it never made any sense to me to put asparagus on a menu in December".

Hopkins quickly found an ally in Grant Anderson, NTU's Environment Manager, who recognized that achieving the Catering Mark would mean extra points for NTU's ranking on the People and Planet University League table. Hopkins notes that the university takes great pride in consistently placing in the top five of the University League, and anything that could help it stay at the top was taken seriously. From his original skepticism, Hopkins moved to a bold decision to go for both the bronze and silver awards at the same time. In 2010, after a grueling seven-hour inspection, NTU became the first university to achieve the silver award. A recent rise in tuition fees across the U.K. has made competition for students more intense, and Hopkins believes the Catering Mark gives NTU an edge [45].

Hopkins was also highly conscious of the need to create a new and different supply chain. To achieve his goals, he started to buy more food directly, rather than through a university bulk-buying consortium. He identified specific products that could come from local farmers and worked with a local produce distribution company, Millside-Barrowcliffe, to purchase local potatoes, carrots, strawberries, and so on. In addition, he sources fair trade and organic coffee, organic eggs, milk and yogurt and Red Tractor Assured meat from Owen-Taylor and Sons Ltd., a regional butcher.

Using more fresh and seasonal products has meant re-thinking the menu. For example, Hopkins recalls being approached by a company offering to supply a burrito "kit", complete with frozen peppers and onions, frozen anonymous beef and chicken and processed salsa. Instead, Hopkins replicated the kit with products that met Catering Mark criteria, including locally-sourced meat, fresh local vegetables and homemade salsa. "We are trying to meet high street trends," Hopkins says. "We can make a superior product by replicating these trends using the Food For Life Catering Mark guidelines" [45].

Hopkins made a serious commitment to using the Catering Mark and provides opportunities to educate students about food issues. Besides colourful posters and website information, "every day the staff get a briefing about all the dishes on the menu, so that they will know what's local and how to talk about the products with students. The best form of communication is person-to-person. If you're making a selection, and someone tells you that those carrots were grown near Newark just up the road, 
that makes a difference" [45]. In addition, Hopkins offers a staff training package every year and takes staff out to visit local suppliers. The author's interviews with chefs and serving staff confirmed these statements. Staff were knowledgeable about the Catering Mark and proud and enthusiastic to share their knowledge [46,47].

Hopkins acknowledges that maintaining the Catering Mark takes work. There is a significant increase in paperwork. In addition, the human side of the work, developing relationships with suppliers and educating staff and students, is time-consuming. However, he is convinced that NTU is on the right track, and he readily speaks with other universities considering the program. He observes that students are responding well; staff are better informed; and "I could quite easily take the Food For Life Catering Award certificate off the wall, but it wouldn't stop carrying on. The certificate is now a bonus for us really" [45]. In other words, the new approach has been embedded in the university's foodservice operations, as well as into its supply chain.

The food supply chain is generally understood as unidirectional, a one-way trip moving from farm to table. Hopkins, in effect, created a two-way supply chain, where he works with suppliers to manage and develop new sources of products. This requires collaboration every step of the way and a new way of thinking about the relationships involved in the food system. As a result, the work that has gone into achieving the Food For Life Catering Mark at NTU has moved the sustainability needle not just on campus, but backwards, among NTU's food suppliers, as well. It has not always been easy. Hopkins says he spent much time nurturing a relationship with a small local egg producer, who eventually closed her doors. However, other relationships are thriving. Suppliers have made significant changes to their product mix and are committed to farm assurance schemes, in order to hold onto, or gain, contracts with NTU.

Anthony Millward is the Managing Director of Millside-Barrowcliffe in Nottingham. His medium-sized company, with 120 employees, sources and distributes fresh produce and processes and vacuum-packs fresh cut vegetables. He is "excited and proud for Ivan for what he has achieved-he's done it for everyone" [48]. Millward says he shifted his buying practices after starting to work with Hopkins and now sources up to $40 \%$ of his produce from local farmers, which he defines as farms located in a 15-mile radius around Nottingham. He is especially proud of graduation days at NTU, when 20,000 students and family members are fed strawberries and sparkling wine over a five-day period. "The berries are picked at $7 \mathrm{am}$. We process them in the morning, and they are at the university for graduation in the afternoon" [48]. This is the pride of a champion and illustrates that agency exists at all levels of the food chain.

John Lupton, another champion of the food supply chain, is the Sales and Marketing Manager at Owen Taylor and Sons Family Butcher, located in Derbyshire, less than 20 miles away from NTU. The firm was established in 1922 and currently has 140 employees, who prepare beef, pork, lamb and poultry to customer specifications for the catering trade. Lupton sees universities as a valuable market with large contracts that provide the company with financial stability, adding "If they all go onto a six-ounce rump steak, we'll be cutting something like three thousand six-ounce rump steaks for delivery in one day, and that's just one meal for that day" [49]. In addition, because universities are closed during December, the university contract permits Owen-Taylor to focus on other clients during the busy holiday season and thereby diversify the client mix.

Lupton says Owen Taylor has been approached to sell to major supermarkets, but has declined because "They end up owning your business. It's too many eggs in one basket. If they drop you, you have no business. But it's a very difficult decision to make because it's lucrative" [49]. Lupton calls Owen-Taylor a "farm to plate" operation, which focuses on buying live animals from local farms (within a 40-mile radius) and having them slaughtered in a local abattoir. The company then cuts the meat to order, for sale to local chefs at restaurants, hotels, hospitals, universities and schools. They serve up to 700 individual clients at any one time. Lupton believes this has preserved skilled jobs in a region of the country that has experienced a significant economic decline after the closure of the coal mines. 
Owen Taylor supplies meat to both NTU and the University of Nottingham, both of which use the Food For Life Catering Mark. According to Lupton, the company had been supplying NTU before it went for Catering Mark certification, and the fact that all of the products meet Red Tractor standards ensured that they could continue the relationship with NTU. He says university clients are a growing part of the business, and meeting Red Tractor standards has made it possible to tender for contracts with institutions using the Food For Life Catering Mark. He says the extra work and cost of certification are worthwhile because certification is increasingly becoming a requirement of institutional contracts.

\subsection{University of the Arts London}

University of the Arts London (UAL) is a multi-campus university with 26,000 students in the heart of London. Considered one of the world's top five universities for art and design [50], UAL brings together six colleges, which feature visual art, design, fashion, communication and performing art under one umbrella. Catering for 19 food outlets over the six locations is overseen by UAL's Head of Retail and Catering, Alastair Johns, and contracted to BaxterStorey, a midsized domestic caterer with a focus on sustainability and provenance. In May 2014, UAL became the first university to achieve the gold Catering Mark.

The decision to go for the gold Catering Mark was spearheaded by Johns. Johns and his colleague Ian Lane, UAL's Head of Sustainability, positioned the changeover as part of an overall sustainability strategy for the university. This attitude is embodied in UAL's Sustainable Food Policy, authored by Johns, which begins with the statement that "The University will create a culture of social and environmental awareness in order to develop and integrate sustainable and ethical policies throughout every aspect of our life and work". The policy goes on to state that "Healthier, ethically sourced, more sustainable food may help to encourage lifestyle changes both inside and outside the university, leading to a positive impact on health and wellbeing, as well as the environment" [51]. Johns says one of the challenges was to convince the university to spend a little more on catering ( $£ 60,000$ in a multi-million $£$ total budget). In addition, there was a $1 \%$ increase in prices charged at food outlets. Johns says students have reacted with enthusiasm, and the cafeterias are full every day.

The contract for catering was won by BaxterStorey, despite the fact that their bid was the highest, because Johns was confident that only an independent company with a reputation for local, seasonal and fresh food could fulfill the university's mandate. Johns was also confident that BaxterStorey could be partners in implementing the program, rather than resisting it, essential to a collaborative relationship. BaxterStorey is the largest independent caterer in the U.K., with several hundred clients, including other universities. Relative to the transnational foodservice companies, BaxterStorey is a midsized firm. However, within the U.K. market, they wield enough buying power that they have been able to influence their own supply chain to ensure that they can source sustainable products from U.K. suppliers, an important example of how university policy can diffuse change throughout the food chain.

Sustainable and organic meats have been the biggest challenge, according to BaxterStorey Operations Manager John Wood. Sustainable bacon was particularly hard to find because low-priced bacon is widely available from other parts of the EU. Wood recalls that "we went to a farmer who could meet Catering Mark standards, and told him we wanted all his pork, to turn it into bacon." Wood says chicken was another challenge. "Free-range chicken is never really commercial, and rare to see within our business, because it's hugely expensive," he says. "But we went to the farmer, and we said 'we are ready to buy 800-1000 chicken legs a week, if you can supply them'" [44]. Wood claims BaxterStorey has been able to create more sustainable supply chains for other products, as well, citing free-range eggs and frozen peas as two examples. These are instances of how high-volume orders can affect the willingness of producers to change both their price points and their product quality level a vivid example of how problem solving and collaboration can take place in a more sustainable system.

Johns says they have dealt with additional costs of higher quality meat by reducing the quantity of meat served. He credits Chef Garret Lynch for his enthusiasm and commitment and his creativity 
in menu planning. "We're on the same wavelength, and we want the same results", says Johns. Testifying to the importance of champions, Johns declares "you can easily get chefs who don't believe in it, and the whole thing will come to a shuddering halt. You need someone of Garret's level to actually drive through what we want driven through" [52].

Lynch understood two operational requirements for more sustainable food systems. One of his innovations was to simplify the menu offerings at smaller outlets with limited kitchen facilities. They serve just two options a day, one vegetarian and one meat-based. This seemingly simple measure has significant impacts. The limited menu controls cost and reduces waste and gives food staff time to prepare meals from scratch. Menus with many offerings usually rely on "heat and eat" prepared foods brought in by distributors. Limiting the menu is an operational necessity in the move to more fresh, seasonal and whole foods, an example of how seemingly minor foodservice changes can become pivotal to important changes further down the food chain.

Lynch also recognized the importance of educating staff so that they, in turn, can educate students. Like Ivan Hopkins at NTU, Lynch ensures that staff at all of the outlets are briefed every day. He notes that students are asking more questions about the food, and he wants his staff to have answers [53]. This is a reflection of the change in relationships as the system becomes more sustainable, and catering increasingly requires relationship- and knowledge-based skills, rather than commodity-handling ones.

Ian Lane, UAL's Head of Sustainability, credits Johns for initiating and driving the change at UAL, but stresses that champions were necessary at every level for the university to achieve the gold Catering Mark. The Vice Chancellor and the chair of the university's Environment Board, as well as operational staff, had to be on board before the go-ahead was given. Lane believes that the Catering Mark repositions the place of food in the university as a sort of "Trojan horse" or wedge for other sustainability initiatives. "Usually universities think about energy or waste as areas for addressing sustainability and corporate social responsibility," Lane reasons. "But food is a great way to keep sustainability front and centre. When you're presented with a complex dynamic challenge like sustainability, I think you need to provide confidence that what you're doing is the right thing and can be easily achieved. Compared to a solar panel which you might see once and forget about, food is your most obvious opportunity to showcase sustainability because you eat food every day" [54]. To this end, Johns ensures that the university's sustainable food achievements are front and centre, with plenty of high profile signage explaining why the university is committed to sustainability in food, how the gold Catering Mark was achieved and exactly which ingredients are used in each dish.

Lane acknowledges that UAL hopes to move up to be among the top three universities in the People and Planet University League this year and that "the university is quite keen to push itself up on that agenda". He contends that "everything we do under the banner of sustainability has to meet the needs of the university, but also deliver a reputational increase" [54]. However, Johns insists that going for the gold Catering Mark was not just about ticking off a box, but that "we did it because we fundamentally believe in it." He argues that the gold Catering Mark helps them to achieve other goals, such as contributing to local economic development and health. "I want to ensure that students have the opportunity to eat decent, healthy food", he says. "When they leave, they may take some of that with them". Johns intuitively understands the multifunctional potential of food when he adds that "offering decent hot food is also about the community and the social space-it's an important part of university life" [52].

An important supplier of vegetables and fruit that ends up in the meals served at UAL is Chegworth Valley Farm, a Kent County organic farm and producer of award-winning farm-pressed apple and fruit juices. The farm is less than 35 miles southeast of London, in a region known as the "Garden of England". The Deme family farms about 300 acres of fruit, as well as vegetables and greens, more than 70 different items in all, which they wholesale to independent stores, restaurants, hotels and caterers for institutional settings, including BaxterStorey. The Demes also run stalls at several London farmers markets, three shops in London that feature organic and local products and a home delivery box scheme that makes daily deliveries throughout London and Kent. The company epitomizes the 
proactive energy that midsize entrepreneurial firms bring to the food system and the role of agency in both the development and diffusion of sustainable practices.

Chegworth Valley Farm features heritage apple varieties, many of which are pressed into juice on-site and often mixed with berries and vegetables for an array of flavours. Although the processing operation is tucked into a small corner of one of the farm buildings, it produces two million bottles of juice a year and earns about half of the farm revenue, according to Marketing Manager Vikki Wright [55]. Wright says hoop houses allow them to extend the growing season for vegetables and berries. At the height of the season, the farm employs 80 people. The farm is certified organic by the Soil Association and is a member of the Catering Mark Supplier Scheme. This means that caterers working toward the gold award can buy products from Chegworth Valley Farm with full confidence that all products are Catering Mark compliant.

\section{Applying the Multi-Level Perspective}

The MLP is a sociotechnical approach to understanding largescale innovations in both production and consumption associated with the sustainability transition [25]. As Smith et al. write, the MLP has a certain allure because "it provides a relatively straight-forward way of ordering and simplifying the analysis of complex, large-scale structural transformations in production and consumption demanded by the normative goal of sustainable development." [25]. In effect, the MLP offers a language and typology for analyzing a wide array of transitions.

The key components of the MLP analysis are the niche, the regime and the landscape. Niches represent the sites where innovations are nested. The regime represents the dominant sociotechnical system. Both the niche and the regime are located within the landscape, the macro-level context of social and physical factors. The landscape is the broader context-social, technical and environmental - that can influence relationships between niches and regimes. The landscape level represents the material context of society (how cities, roads, energy infrastructure, institutions, etc., are configured), as well as a mix of additional factors, such as climate change, wars, oil prices, water availability, emigration and cultural values [19]. The interaction of niches, regimes and landscape comes into play during the sustainability transition.

For purposes of this article, the niche is the Food For Life Catering Mark, and the regime is the industrial food system as applied to universities. The post-1980s industrial food system is a global force dominated by transnational corporations and their subsidiaries, what McMichael has described as the "third food regime" [56]. The landscape is British traditions, institutions and discourses.

\subsection{Enriching the Conceptualization of the Landscape: The Importance of the Public Agenda}

This article contends that the concept of the landscape in the MLP is a major contribution to understanding food system transitions, because the broad landscape has a telling impact on innovation in its own right, quite apart from the food regime. The argument here is that five factors in the U.K. landscape "set the stage" for the development of the Food For Life Catering Mark. The first of these is the policy environment that prevailed at the time. The second is a forceful green movement among university students. The third is a long-established and well-funded lead civil society organization that pre-dated the rise of the wider food and sustainability movement. The fourth is the existence of a national school meal program at the primary and secondary level, a feature of U.K. society since the end of World War II which underwent a significant decline in food quality and nutrition as a result of government demands for cost reductions [33]. The fifth is the pre-existence of recognized food production standards relating to sustainability and traceability. The combination of these five factors brought the campaign for changing university meals toward a national discourse and galvanized sufficient attention to get action. In other words, the landscape allowed the Catering Mark to gain a niche and break from the confines of the typically marginalized constituency for healthy and sustainable food issues. 


\subsubsection{The Policy Environment}

There is currently a "warm policy environment" in the U.K. around issues relating to health and environment, says Rob Percival, Policy Officer at the Soil Association [17]. Several elements unique to the U.K. contribute to this warm policy environment. To begin with, there is only one national government to deal with on issues related to food and the environment, rather than the fragmented mix of national and provincial/state jurisdictions found in North America.

Secondly, environmentally-based concerns about food have an automatic legitimacy in the U.K because the government department in charge of food policy goes by the name of DEFRA, the Department for Environment, Food and Rural Affairs. This is in contrast with North American agriculture departments, which focus on agriculture as a commodity and do not even mention the environment (e.g., the USDA, United States Department of Agriculture, and OMAFRA, Ontario Ministry of Agriculture, Food and Rural Affairs). As a result of the embedded mandate and duty of the U.K.'s DEFRA, the Soil Association is regularly invited to participate in stakeholder consultations and to air issues related to the environment. This is an avenue of engagement not available to North American food and sustainability leaders. Consequently, the impact of the Food For Life Catering Mark can be found in several government documents providing guidelines for procurement in schools, the hospital sector and the public sector generally, all of which reference the Catering Mark as a tool to support good procurement practices $[2,57,58]$.

Percival also credits organizations such as Sustain: The Alliance for Better Food and Farming, another civil society organization that advocates for better food policy. Prior to the establishment of the Catering Mark, Sustain led a high-profile national campaign to improve school meals. The existence of such strong civil society organizations is a significant factor in the landscape affecting sustainable food system development.

\subsubsection{A Strong Student Movement}

Another civil society organization that set the stage for university interest in the Catering Mark is People and Planet, a network of university student groups, which campaigns to "end world poverty, defend human rights and protect the environment" [29]. Like Oxfam before it, People and Planet developed in the 1970s out of student activism at Oxford University. Today, there are chapters at universities across the U.K. People and Planet is supported by a small permanent staff, still based in Oxford.

The organization originally focused on global campaigns, such as sweatshops and climate change. However, in 2003, People and Planet decided to launch a domestic campaign to green university campuses as a response to climate change. Thus was born the University League (formerly the Green League), which rates all universities in the U.K. for environmental and ethical performance, including food procurement. Hannah Smith, the Co-Director of Campaigns for People and Planet, says the University League enjoyed immediate uptake. "The university sector responded very fast and very obviously", she said. "Some universities really threw resources into achieving" [59].

The University League was launched in 2007, with rankings of every publically-funded institution of higher education in the U.K. The first table was published in the Times Higher Education supplement. A partnership with The Guardian newspaper was later established. Publication in two of the most influential newspapers in the English-speaking world attests to the impact and reach of this student organization and its ability to shape a national discourse linking ethical and environmental issues with universities. The Food For Life Catering Mark is referenced in the University League and provides the basis for a positive rating of the food component.

The existence of an environmentally-friendly student movement with society-wide impact and a commitment to sustainable food systems has been a major landscape factor in encouraging universities to introduce the Food For Life Catering Mark. Evidence from many interviews confirms that the desire to move up in the rankings of the People and Planet University League was an important pressure point for advocates of the Catering Mark. 


\subsubsection{A Long-Established and Well-Funded Lead Civil Society Organization}

It is also a significant landscape factor that the Catering Mark is an initiative of the Soil Association, a highly capable and well-connected civil society organization focused on food and health in the U.K. Founded in 1946, the Soil Association pre-dates the current food and sustainability movements by several decades. Although the organization is well known for its work as an organic certifier, it is much more than a certifying body or trade organization. It has a history of campaigning on high profile issues related to health and food quality, such as the overuse of antibiotics in livestock farming. According to the Soil Association Policy Director, Peter Melchett, it was "as much a health charity concerned about the quality of the food that the poorest people were having to eat as a farming charity when it started ...., and actually, the work we've done on school meals is probably closest to some of the earliest work the Soil Association did" [60].

The facts that the Soil Association was established decades before the rise of the current food movement, has secure funding and can attract staff of the calibre of Peter Melchett (a former Labour Government Minister in the Departments of Environment, Industry and Northern Ireland from 1974-1979, the former Director of Greenpeace U.K. from 1985-2000 and a member of the House of Lords), lend considerable weight to the Soil Association's work.

\subsubsection{A National School Meal Program}

The U.K.'s national school meal program is another important landscape factor. Introduced shortly after World War II, it has become a fixture of British society and enjoys popular consensus. The national school meal program resonates with the general public because it represents society's duty of care for its most endearing and vulnerable citizens: children. One indication of its stature in the British psyche is the universal awareness of celebrity chef Jamie Oliver's criticism and call to action. The existence of a highly-valued national school meal program ensured that there was a space in the national discourse about school meal quality that could not be dismissed as a marginal concern of a narrow interest group. The limelight created by general discontent with school meal quality was a major background factor behind the establishment of the Food For Life Program, which led to the Food For Life Catering Mark.

\subsubsection{The Pre-existence of Recognized Production Standards}

The existence in the U.K. of a number of production standards for quality, sustainability, animal welfare and farm assurance (Red Tractor Assurance, Freedom Food, Fairtrade, Organic and Marine Stewardship Council) meant that those writing the Catering Mark standards did not have to start from scratch, but were able to draw on expertise from a variety of sources. This reduced research costs and added legitimacy to the standards. In addition, incorporating existing standards was a way to engage and build bridges with mainstream and other organizations that might not have been immediately supportive of the Soil Association's goals. Pre-existing production standards are a landscape factor because they created conditions for cooperation and better acceptance of the Catering Mark scheme.

\subsection{Creating Space for Innovation through Conflict at the Landscape Level}

The MLP's attention to landscape helps us appreciate the range of variables capable of generating an environment conducive to food reforms, independent of both the regime and the niche. Landscape factors are especially critical in the food sector. Such is the power of global corporate control of the food system that niche challenges to the regime may not be viable unless space is created by conflict within the landscape. This is because transnational food corporations drive prices down by using their enormous aggregate purchasing power and by externalizing social and environmental costs of cheap food [61-68].

Destabilization in the food landscape is critical for opening up spaces for niches. For this reason, it is essential to look beyond the food regime to the wider food landscape in order to understand how sustainability transition gained a toehold in a monopoly-dominated food system. In other words, if the 
Food For Life Catering Mark did not have a secure launching pad in public discourse, it was unlikely to gain a toehold in a university niche. This dependence of the niche on landscape factors may be especially pronounced in the food sector, where corporate power is so concentrated and price and convenience are such defining competitive advantages. However, if the MLP is to be applied to food, it must take such factors into account.

Geels et al. acknowledge that the transition process is "open, uncertain and non-linear." [69] Elsen et al. refer to "transitions in the making" where "the initial impulse for change consists of normative contestation from regime outsiders" [70]. This means that in some types of transitions, sustainability being a case in point, the innovation process faces a rocky road, often requiring conflict and mobilization. Geels himself anticipates this in recent radical amendments to the MLP [28], in an argument that supports the analysis presented here.

In earlier MLP iterations, Geels regards the interaction among levels as an "alignment process" [69] and argues that "increases in normative pressure are likely to have more effect on transitions if they coincide with and can become linked to other developments, leading to a particular 'package' that can be pushed through" [69]. He summarizes the transition process this way: "niche-innovations build up internal momentum (through learning processes, price/performance improvements, and support from powerful groups); changes at the landscape level create pressure on the regime; and destabilization of the regime creates windows of opportunity for the diffusion of niche-innovations. The alignment of these processes enables the breakthrough of 'green' innovations in mainstream markets where they struggle with the existing regime on multiple dimensions (economic, technical, political cultural, infrastructural" [28]. However, Geels later goes on to critique his own conceptualization of alignment as minimizing the role of power and politics and not recognizing that regime actors may actively resist transition by preventing the formation of effective niches.

The incumbent food regime is convenient and cheap, two significant advantages for institutions. The offering of the global foodservice corporations includes a turn-key operation for institutional clients. This means that food can be designated an ancillary service to be offloaded to one of the global corporations. The president of the university does not have to worry about what students are eating; chefs and administrators do not have to worry about the supply chain and the availability of food; food safety criteria will be met, and prices will be acceptable. Unless there is a new way to talk about food, what Morgan and Sonnino call a "new food equation" [71], the old way will prevail because it is simply easier.

For a different paradigm of foodservice to take hold, there must be appreciation for the multifunctionality of food [72] and its ability to address the landscape-related factors bearing on the health, economic, environmental, social, cultural and reputational goals of the institution. Innovations such as the Food For Life Catering Mark become more viable when universities understand that these innovations will provide a direct advantage on many fronts, sufficient to compensate for losses in convenience and price.

\subsection{Enriching the Conceptualization of the Niche: the Role of Champions}

A dominant element of the experience of introducing the Food For Life Catering Mark at Nottingham Trent University and University of the Arts London was the central role played by individual champions. Champions, or change agents, embraced the cause, became highly effective advocates and went beyond their job requirements to see it through. Introducing the Food For Life Catering Mark meant more work, more cost, more intentionality, more engagement, more risk and more going beyond job definitions on the part of many champions at many levels of the institution, including among suppliers. Yet, champions came forward. The MLP can be enriched by recognizing that niches are actually created by human agency. Human agency must be foregrounded in this analysis. Agency in the food sector takes a specific form: the champion or change agent who drives operationalization.

This article supports a new formulation of the relationship between the niche and the regime, arguing that values-based innovation in the food sector is disruptive and inherently involves conflict. 
Innovators construct new pathways. In other words, the change process around sustainable and local food is not primarily a narrative about alignment, but about contestation. It is not simply a matter of harmonization in the adoption of new standards. Rather, it is an active and on-going process of contestation, which requires skilled, intentional and proactive human agency.

A review of the history of the Food For Life Catering Mark confirms that it is not only the head of the university who must be on board, but also the head chef, who is willing to turn down the benefits of a turn-key operation and put time and energy into reconstructing a different supply chain. There must also be buy-in from individuals all along the chain. These might include anyone from the head of sustainability to the serving staff, as well as distributors, processors and farmers.

To appreciate the importance of the Soil Association's development of the Catering Mark, it must be recognized that the benefits gained from achieving the Catering Mark are distributive, not direct. Unlike the energy sector, where building insulation leads to direct reductions in energy costs and a calculable return on investment, the benefits of a more sustainable food system are diffused in many ways and directions. These benefits might include a healthier student population, more local jobs, a healthier environment, a stronger food culture and a favourable reputation for the institution. However, few of these benefits can be tracked directly to a balance sheet that delivers exclusive dividends to a specific person or department, the syndrome of creating a "collective action failure", as outlined in the political science classic, The Logic of Collective Action: Public Goods and the Theory of Groups [73]. Far from creating exclusive benefits for caterers, costs and workload are likely to rise. Therefore, there must be champions willing to fight for the principle of sustainability transition. This highlights the champion role of the lead civil society organization, the Soil Association, which had the creativity, the insight, the commitment, the funding and the capacity to develop and carry the Food For Life Program and the Food For Life Catering Mark.

Besides initiating the sustainability transition, champions ensure its continuation. As Hannah Smith, Co-Director of Campaigns for People and Planet, notes, "the whole sustainability agenda is still vulnerable, still not embedded enough in the higher education sector, still precarious, still dependent on champions". Smith goes on to argue that "when there are cuts to funding, or when the government is not encouraging best practice in this area, we see it disappear from institutions. Where it doesn't disappear and continues to evolve in a positive way, even without those drivers, it's because there are champions at that university" [59].

These observations suggest that sustainability requires a driver willing and able to withstand pushback from the incumbent regime. Sustainability innovations such as the Food For Life Catering Mark are "disruptive innovations" [74], which disrupt the existing business model and come from the outside. Innovations, such as the Food For Life Catering Mark, offer "a different package of attributes valued only in emerging markets remote from, and unimportant to, the mainstream" [74], and threaten privilege in the existing sociotechnical regime, a defining precondition of disruptive innovation.

\section{Conclusions}

Data collected for this article indicate that sustainability transition in the food sector is complex, difficult, labour-intensive and detail-rich. Recognizing this reality, the article proposes that operationalization and implementation of the sustainability transition must themselves be problematized and theorized. The same case can be made for understanding and integrating the role of the champions who manage the transition, from advocacy campaigns to implementation. Close attention to operational detail in institutional food procurement can enrich the understanding of the logistics behind the dominant food system, as well as the challenges and barriers facing sustainability transition and the requirements of leadership. To adapt sustainability transition theory to the food industry, we must also appreciate that the food sector is a sector of relentless deadlines. The food itself is perishable, and the customers demand immediate service. There is not much space for dry runs and dress rehearsals. Consequently, those leading change efforts have to think through 
and plan for hundreds of details. Practitioner-champions are fundamental sources of information about this, and studying their experience expands our understanding of the transition journey.

Appreciating implementation is especially important when analyzing sustainability transitions that involve continuous improvement. The complexity of this is not readily grasped by consumers or food policy analysts, few of whom have experience with the intricacies of logistical decisions. The Food For Life Catering Mark is a case study of the role of continuous improvement in the sustainability transition. Changes that make the certification more difficult to attain cannot be made lightly. If the infrastructure is not there, the whole program can unravel. As an example, consider the effort of the Food For Life Catering Mark team to include free-range eggs as a new requirement at the bronze level. Project Manager Jen Collins says before making this seemingly simple change, it was necessary to find out if an adequate supply of free-range eggs were available in the U.K. Specifically, they needed to know if both shell eggs and liquid eggs (for making large quantities of scrambled eggs and omelettes, for example) existed in adequate quantity. To do this, the Catering Mark team ran a public consultation and consulted with the egg industry and caterers using the Catering Mark. In order to accommodate concerns raised about cost and availability, Collins says the Soil Association decided to give caterers an 18-month implementation period [30]. Food practitioners learn through such experiences not to count their chickens before they are hatched!

On the surface, the Food For Life Catering Mark represents a "disruptive innovation" to the incumbent global food regime. By requiring freshly-prepared foods with seasonal ingredients, it challenges the global food regime that relies on volume purchases of standardized low-cost processed food without provenance. However, as this article points out, the university staff applying the Catering Mark are doing more than disrupting the existing food regime. They are also consciously constructing new supply chain mechanisms for a new regime, by pushing back through the supply chain to find the products and build the infrastructure they need. This detailed and complex process is at the heart of implementation and is so central to sustainability transition that it deserves both recognition and deeper understanding. At the theoretical level, the Food For Life Catering Mark is a leading example of how this process can be managed in public institutions.

Acknowledgments: I would like to thank the interviewees who gave so generously of their time and knowledge, my thesis supervisor Alison Blay-Palmer for her ongoing advice and support, and the reviewers. I would also like to thank the Social Science and Humanities Research Council of Canada, Wilfrid Laurier University and the Laurier Centre for Sustainable Food Systems.

Conflicts of Interest: The author declares no conflict of interest.

\section{References}

1. Morgan, K.; Morley, A. The public plate: Harnessing the power of purchase. In Sustainable Food Systems: Building a New Paradigm; Routledge: London, UK, 2014; pp. 84-102.

2. DEFRA A Plan for Public Procurement: Food and Catering: Balanced scorecard for public food procurement. Available online: https://www.gov.uk/government/uploads/system/uploads/attachment_data/file/ 419245/balanced-scorecard-annotated-march2015.pdf (accessed on 9 June 2016).

3. DEFRA Food Statistics Pocketbook 2015. Available online: https://www.gov.uk/government/uploads / system/uploads/attachment_data/file/526395/foodpocketbook-2015update-26may16.pdf (accessed on 6 June 2016).

4. Lin, B.-H. USDA Economic Research Service-Food-Away-from-Home. Available online: http://www.ers. usda.gov/topics/food-choices-health/food-consumption-demand/food-away-from-home.aspx (accessed on 3 June 2016).

5. Friedmann, H. Scaling up: Bringing public institutions and food service corporations into the project for a local, sustainable food system in Ontario. Agric. Hum. Values 2007, 24, 389-398. [CrossRef]

6. Morgan, K. Greening the Realm: Sustainable Food Chains and the Public Plate. Reg. Stud. 2008, 42, 1237-1250. [CrossRef]

7. Roberts, W.; Archibald, S.; Colson, C. Sharing Out the Campus Food Systems Project; Meal Exchange: Toronto, ON, Canada, 2014. 
8. Bagdonis, J.M.; Hinrichs, C.C.; Schafft, K.A. The emergence and framing of farm-to-school initiatives: Civic engagement, health and local agriculture. Agric. Hum. Values 2008, 26, 107-119. [CrossRef]

9. Conner, D.S.; Izumi, B.T.; Liquori, T.; Hamm, M.W. Sustainable school food procurement in large K-12 districts: Prospects for value chain partnerships. Agric. Resour. Econ. Rev. 2012, 41, 100.

10. Izumi, B.T.; Wright, D.W.; Hamm, M.W. Farm to school programs: Exploring the role of regionally-based food distributors in alternative agrifood networks. Agric. Hum. Values 2009, 27, 335-350. [CrossRef]

11. Joshi, A.; Azuma, A.M.; Feenstra, G. Do Farm-to-School Programs Make a Difference? Findings and Future Research Needs. J. Hunger Environ. Nutr. 2008, 3, 229-246. [CrossRef]

12. Morgan, K.; Sonnino, R. The School Food Revolution: Public Food and the Challenge of Sustainable Development; Earthscan: Sterling, VA, USA, 2008.

13. Morgan, K.; Sonnino, R. Empowering consumers: The creative procurement of school meals in Italy and the UK. Int. J. Consum. Stud. 2007, 31, 19-25. [CrossRef]

14. Orme, J.; Jones, M.; Kimberlee, R.; Salmon, D.; Weitkamp, E.; Dailami, N.; Morgan, K.; Morley, A.; Smith, A. Food for Life Partnership Evaluation Full Report; Food for Life Partnership: Bristol, UK, 2010.

15. Stein, M. Public Sector Food Procurement and Sustainability in UK Schools. In Producing and Reproducing Farming Systems. New Modes of Organisation for Sustainable food Systems of Tomorrow, Proceedings of the 10th European IFSA Symposium, Aarhus, Denmark, 1-4 July 2012; International Farming Systems Association: Vienna, Austria, 2012.

16. The Soil Association-About Us. Available online: https://www.soilassociation.org/about-us/ (accessed on 26 May 2016).

17. Percival, R. (Soil Association, Bristol, UK). Personal communication, 2015.

18. The Soil Association. The Road to 2020: Towards Healthy, Humane and Sustainable Food, Farming and Land Use; The Soil Association: Bristol, UK, 2011.

19. Geels, F.W. Technological transitions as evolutionary reconfiguration processes: A multi-level perspective and a case-study. Res. Policy 2002, 31, 1257-1274. [CrossRef]

20. Spaargaren, G.; Loeber, A.; Oosterveer, P. (Eds.) Food Practices in Transition: Changing Food Consumption, Retail and Production in the Age of Reflexive Modernity; Routledge: New York, NY, USA, 2012.

21. Business Dictionary What Is a champion? Definition and Meaning. Available online: http://www. businessdictionary.com/definition/champion.html (accessed on 29 August 2016).

22. Grin, J.; Rotmans, J.; Schot, J. On patterns and agency in transition dynamics: Some key insights from the KSI programme. Environ. Innov. Soc. Transit. 2011, 1, 76-81. [CrossRef]

23. Lawhon, M.; Murphy, J.T. Socio-technical regimes and sustainability transitions: Insights from political ecology. Prog. Hum. Geogr. 2012, 36, 354-378. [CrossRef]

24. Smith, A.; Stirling, A.; Berkhout, F. The governance of sustainable socio-technical transitions. Res. Policy 2005, 34, 1491-1510. [CrossRef]

25. Smith, A.; Voß, J.-P.; Grin, J. Innovation studies and sustainability transitions: The allure of the multi-level perspective and its challenges. Res. Policy 2010, 39, 435-448. [CrossRef]

26. Spaargaren, G. Sustainable Consumption: A Theoretical and Environmental Policy Perspective. Soc. Nat. Resour. 2003, 16, 687-701. [CrossRef]

27. Geels, F.W. The multi-level perspective on sustainability transitions: Responses to seven criticisms. Environ. Innov. Soc. Transit. 2011, 1, 24-40. [CrossRef]

28. Geels, F.W. Regime Resistance against Low-Carbon Transitions: Introducing Politics and Power into the Multi-Level Perspective. Theory Cult. Soc. 2014, 31, 21-40. [CrossRef]

29. About People \& Planet. People \& Planet. Available online: https://peopleandplanet.org/aboutus/ (accessed on 29 May 2016).

30. Collins, J. (Soil Association, Bristol, UK). Personal communication, 2015.

31. Morse, J.M. Insight, inference, evidence, and verification: Creating a legitimate discipline. Int. J. Qual. Methods 2008, 5, 93-100.

32. Orme, J.; Jones, M.; Kimberlee, R.; Weitkamp, E.; Salmon, D.; Dailami, N.; Morley, A.; Morgan, K. Food for Life Partnership Evaluation: Summary Report; University of the West of England: Bristol, UK, 2011.

33. The Soil Association. Food For Life: Healthy, Local, Organic School Meals; The Soil Association: Bristol, UK, 2003.

34. Food For Life Big Lottery Fund-Food for Life. Available online: http://www.foodforlife.org.uk/about-us/ our-supporters/big-lottery-fund (accessed on 29 August 2016). 
35. Orrey, J. (Soil Association, Bristol, UK). Personal communication, 2015.

36. Kersley, H.; Knuutila, A. The Benefits of Procuring School Merals through the Food For Life Partnership: An Economic Analysis; The New Economics Foundation: London, UK, 2011.

37. The Soil Association. The Food For Life Catering Mark Standards Handbook for Universities; The Soil Association: Bristol, UK, 2015.

38. Shingler, S. (Soil Association, Bristol, UK). Personal communication, 2015.

39. Great for Suppliers and Caterers. Available online: https://www.soilassociation.org/certification/the-foodfor-life-catering-mark/the-catering-mark-supplier-scheme/great-for-suppliers-and-caterers/ (accessed on 9 June 2016).

40. Morgan, K. The Politics of the Public Plate: School Food and Sustainability. Int. J. Sociol. Agric. Food 2014, 21, 253-260.

41. Thomas, P. Soil Association Resignation. Howl at the Moon. Available online: http://www.howlatthemoon. org.uk/index.php?p=1_78 (accessed on 4 June 2016).

42. Vaughan, A. Soil Association has disowned "O word", say resigning trustees. The Guardian, 1 December 2014; E1.

43. Soil Association. Available online: https://www.soilassociation.org/certification/the-food-for-life-cateringmark/sectors/universities-colleges/ (accessed on 13 May 2013).

44. Wood, J. (BaxterStorey, London, UK). Personal communication, 2015.

45. Hopkins, I. (Nottingham Trent University, Nottingham, UK). Personal communication, 2015.

46. Barnaby, I. (Nottingham Trent University, Nottingham, UK). Personal communication, 2015.

47. Chatfield, S. (Nottingham Trent University, Nottingham, UK). Personal communication, 2015.

48. Millward, A. (Millside-Barrowcliffe, Nottingham, UK). Personal communication, 2015.

49. Lupton, J. (Owen-Taylor and Sons Family Butcher, Leabrooks, Derbyshire, UK). Personal communication, 2015.

50. QS World University Rankings QS World University Rankings by Subject 2016-Art \& Design. Available online: http://www.topuniversities.com/university-rankings/university-subject-rankings/2016/ art-design (accessed on 8 June 2016).

51. Sustainability-Food-Policy-v2. Available online: http://www.arts.ac.uk/media/arts/about-ual/ sustainability/Sustainability-Food-Policy-v2.pdf (accessed on 8 June 2016).

52. Johns, A. (University of the Arts London, London, UK). Personal communication, 2015.

53. Lynch, G. (BaxterStorey, London, UK). Personal communication, 2015.

54. Lane, I. (University of the Arts London, London, UK). Personal communication, 2015.

55. Wright, V. (Chegworth Valley Farm, Harrietsham, Kent, UK). Personal communication, 2015.

56. McMichael, P. Global development and the corporate food regime. Res. Rural Sociol. Dev. 2005, 11, 265.

57. Department of Health. A Toolkit to Support the Development of a Hospital Food and Drink Strategy; Department of Health: London, UK, 2016.

58. School Food Plan. School Food Standards; School Food Plan: London, UK, 2016.

59. Smith, H. (People and Planet, Oxford, UK). Personal communication, 2015.

60. Melchett, P. (Soil Association, Bristol, UK). Personal communication, 2015.

61. Appleby, M.C.; Cutler, N.; Gazzard, J.; Goddard, P.; Milne, J.A.; Morgan, C.; Redfern, A. What price cheap food? J. Agric. Environ. Ethics 2003, 16, 395-408. [CrossRef]

62. Clapp, J.; Fuchs, D.A. (Eds.) Corporate Power in Global Agrifood Governance; MIT Press: Cambridge, MA, USA, 2009.

63. Constance, D.H.; Hendrickson, M.; Howard, P.H.; Heffernan, W.D. Economic Concentration in the Agrifood System: Impacts on Rural Communities and Emerging Responses. In Rural America in a Globalizing World: Problems and Prospects for the 2010s; West Virginia University Press: Morgantown, WV, USA, 2014.

64. Howard, P.H. Consolidation in the North American Organic Food Processing Sector, 1997 to 2007. Int. J. Sociol. Agric. Food 2009, 16, 13-30.

65. Lyson, T.A.; Raymer, A.L. Stalking the wily multinational: Power and control in the US food system. Agric. Hum. Values 2000, 17, 199-208. [CrossRef]

66. Martin, S.; Andrée, P. The "Buy-Local" Challenge to Institutional Foodservice Corporations in Historical Context. J. Agric. Food Syst. Community Dev. 2012. [CrossRef]

67. O'Kane, G. What is the real cost of our food? Implications for the environment, society and public health nutrition. Public Health Nutr. 2011, 15, 268-276. [CrossRef] [PubMed] 
68. Roberts, W. The No-Nonsense Guide to World Food; Between the Lines: Toronto, ON, Canada, 2013.

69. Geels, F.W.; Verhees, B. Cultural legitimacy and framing struggles in innovation journeys: A cultural-performative perspective and a case study of Dutch nuclear energy (1945-1986). Technol. Forecast. Soc. Chang. 2011, 78, 910-930. [CrossRef]

70. Elzen, B.; Geels, F.W.; Leeuwis, C.; van Mierlo, B. Normative contestation in transitions "in the making": Animal welfare concerns and system innovation in pig husbandry. Res. Policy 2011, 40, 263-275. [CrossRef]

71. Morgan, K.; Sonnino, R. The Urban Foodscape: World Cities and the New Food Equation. Camb. J. Reg. Econ. Soc. 2010, 3, 209-224. [CrossRef]

72. Blay-Palmer, A. Alternative land use services and the case for multifunctional policy in Canada. In Health and Sustainability in the Canadian Food System: Advocacy and Opportunity for Civil Society; UBC Press: Vancouver, BC, Canada, 2012; pp. 39-69.

73. Olson, M. The Logic of Collective Action: Public Goods and the Theory of Groups; Harvard University Press: Cambridge, MA, USA, 1965.

74. Christensen, C.M. The Innovator's Dilemma: The Revolutionary Book that Will Change the Way You Do Business; HarperCollins: New York, NY, USA, 2003.

(C) 2016 by the author; licensee MDPI, Basel, Switzerland. This article is an open access article distributed under the terms and conditions of the Creative Commons Attribution (CC-BY) license (http://creativecommons.org/licenses/by/4.0/). 